\title{
Influência da presença da bordadura e dos níveis de água na evaporação obtida em minievaporímetros ${ }^{1}$
}

\author{
Cristiano Tagliaferre ${ }^{2}$, Rubens Alves de Oliveira ${ }^{3}$, Gilberto Chohaku Sediyama ${ }^{3}$, Paulo Roberto Cecon ${ }^{4}$, \\ Franklin José Valbuena Materán ${ }^{5}$, Mauro Aparecido Martinez ${ }^{3}$
}

\begin{abstract}
RESUMO
Este trabalho objetivou avaliar a influência de bordadura com água e diferentes profundidades do nível de água dentro do evaporatório dos minievaporímetros UFV-1 e UFV-2 sobre a evaporação. Para analisar o efeito da bordadura e das profundidades dos níveis de água iguais a 30,45, 60 e $75 \mathrm{~mm}$ da borda nos minievaporímetros, o experimento foi montado em esquema fatorial 4 x 2 (quatro níveis de água e dois tipos de minievaporímetros), no delineamento inteiramente casualizado, com três repetições. De acordo com os resultados, a bordadura com água reduziu a evaporação no minievaporímetro UFV-2 em 1,10 $\mathrm{mm} \mathrm{d}^{-1}$, em média, nas diferentes profundidades dos níveis de água estudados, comparativamente ao minievaporímetro UFV-1. À medida que se aumentou a profundidade do nível de água no evaporatório dos dois tipos de minievaporímetros, a evaporação diminuiu e se aproximou do valor obtido no tanque Classe A. O aumento na profundidade dos níveis de água nos minievaporímetros UFV-1 e UFV-2 de 30 para 75 mm reduziu a evaporação de 5,45 para 4,9 $\mathrm{mm} \mathrm{d}^{-1}$ e de 4,29 para 3,81 $\mathrm{mm} \mathrm{d}^{-1}$, respectivamente.
\end{abstract}

Palavras-chave: Evaporímetro, evapotranspiração de referência, tanque de evaporação.

\begin{abstract}
Influence of fetch conditions and water levels on evaporation measured by minievaporimeters

The objective of this work was to evaluate the influence of the water fetch area and different depths of water in the evaporation pan of the minievaporimeters UFV-1 and UFV-2 on total water evaporation. To analyze the fetch effect and water depths at 30, 45, 60 and $75 \mathrm{~mm}$ of the top of the pan, an experiment was arranged in a factorial $4 \times 2$ (four levels of water and two types of minievaporimeters) in a complete randomized design, with three replications. Results showed that the water fetch area reduced evaporation in the minievaporimeter UFV-2 by $1.10 \mathrm{~mm} \mathrm{~d}^{-1}$, on average, at the different water depths, compared with the minievaporimeter UFV-1. Increasing the water depth in the evaporation pan of the two minievaporimeters, led to a decrease in evaporation that came close to values obtained by the Class A pan evaporimeter. The increase in water depth in both minievaporimeters UFV-1 and UFV-2 from 30 to $75 \mathrm{~mm}$ reduced evaporation rates from 5.45 to $4.9 \mathrm{~mm} \mathrm{~d}^{1}$ and from 4.29 to $3.81 \mathrm{~mm} \mathrm{~d}^{-1}$, respectively.
\end{abstract}

Key words: Evaporimeter, reference evapotranspiration, evaporation pan.

Recebido para publicação em novembro de 2007 e aprovado em dezembro de 2010

'Parte da tese de Doutorado apresentada pelo primeiro autor à Universidade Federal de Viçosa (UFV).

${ }^{2}$ Engenheiro-Agrônomo, Doutor. Universidade Estadual Sudoeste da Bahia, DEAS/UESB, Departamento de Engenharia Agrícola e Solos, 45083-900, Vitória da Conquista, Bahia, Brasil.tagliaferre@yahoo.com.br

${ }^{3}$ Engenheiro Agrícola, Doutor. Universidade Federal de Viçosa, Departamento de Engenharia Agrícola, DEA/UFV, Avenida P.H.Rolfs, s/n, Campus Universitário, 36570-000, Viçosa, Minas Gerais, Brasil. rubens@ufv.br; g.sediyama@ufv.br, mmauro@ufv.br

${ }^{4}$ Engenheiro-Agrônomo, Doutor. Universidade Federal de Viçosa, Departamento de Informática, DPI/UFV, Avenida P.H.Rolfs, s/n, Campus Universitário, 36570-000, Viçosa, Minas Gerais, Brasil. cecon@dpi.ufv.br

${ }^{5}$ Engenheiro-Agrônomo, Doutor. Faculdade de Agronomia da Universidad Del Zulia, Departamento de Engenharia de Solos e Água, Maracaíbo-Venezuela. franklin@yahoo.com.br 


\section{INTRODUÇÃO}

A evaporação é um processo físico dependente da energia disponível no ambiente. A medida da evaporação de uma superfície de água livre, de acordo com Valero \& Mañas (1993), deve integrar as diferentes condições climáticas que influenciam o processo da evapotranspiração.

A evapotranspiração de referência pode ser determinada por evaporímetros de diversos tipos, referentes à forma, à dimensão, ao material de constituição e ao volume de água armazenada. O evaporímetro de Piche e o tanque Classe A destacam-se por serem de uso mais fácil quando comparado com os modelos usados para estimar a demanda evaporativa da atmosfera ou a evapotranspiração de referência (Valero \& Mañas, 1993).

A avaliação quantitativa da evaporação de água de superfícies naturais é importante para o planejamento, a construção e operação de reservatórios, represas e sistemas de irrigação e drenagem. Gangopadhyaya et al. (1966) e Hounam (1973) descreveram diversos tipos de tanques evaporimétricos usados para medir a evaporação da água de superfícies naturais, incluindo-se os tanques de $20 \mathrm{~m}^{2}$, GGI 3000, Colorado, BPI e Classe A. De acordo com esses autores, a evaporação que ocorre nos tanques maiores, por exemplo o de $20 \mathrm{~m}^{2}$, aproxima-se da que acontece nos lagos naturais, enquanto nos menores ela é superestimada, necessitando de um coeficiente de correção ou de ajuste, obtido pela relação com o tanque de $20 \mathrm{~m}^{2}$, usado como padrão (Sleight, 1917; Gangopadhyaya et al., 1966). De modo semelhante, estudos posteriores foram conduzidos por Doorenbos \& Pruitt (1977), visando converter a evaporação obtida em tanques menores, como o Classe A e o Colorado, em evapotranspiração de referência, com o uso de coeficientes dependentes do tamanho, da forma e das condições de instalações do tanque, além das condições climáticas locais.

Sleight (1917), trabalhando com tanques enterrados e com área fixa, correspondente ao diâmetro de 0,61 m, mas variando a profundidade do tanque de 0,08 até $1,75 \mathrm{~m}$, verificou que não houve diferença significativa nas taxas de evaporação. No entanto, Hounam (1973) e Kohler \& Parmele (1967) afirmaram que, devido à capacidade dos lagos profundos em armazenar calor, a profundidade do lago exerce influência na variação diária e sazonal da taxa de evaporação.

Outro aspecto importante que deve ser considerado na instalação dos tanques evaporimétricos, como o Classe A, é a altura de exposição sobre o solo. Estudos conduzidos por Pruitt, citado por Camargo \& Camargo (2000), em regiões de clima árido nos Estados Unidos, apontaram que quando o tanque Classe A foi montado elevado cerca de $40 \mathrm{~cm}$ de altura a evaporação foi de $1.081 \mathrm{~mm}$, em um ano. No mesmo tanque, quando enterrado e com superfí- cie evaporante ao nível do solo, a evaporação foi de 834 $\mathrm{mm}, 23 \%$ a menos. De acordo com Camargo \& Camargo (2000), a maior evaporação nos tanques elevados se deve, certamente, à grande exposição de suas paredes à radiação solar e ao vento.

Nota-se que são poucas as informações sobre a influência da variação do nível da água dentro do tanque sobre a evaporação, assim como a utilização de bordadura constituída por água usada ao redor do evaporatório e, principalmente, por seus efeitos na evaporação. As abordagens relatam sobre bordaduras formadas de grama ou de solo descoberto circundando o tanque Classe A, cuja finalidade é evitar que a advecção de calor sensível influencie significativamente o processo de evaporação ou evapotranspiração, principalmente em regiões áridas (Monteny, 1972; Rosenberg, 1972; Prueger et al., 1996).

Diante do exposto, este trabalho objetivou avaliar a influência da presença de bordadura com água e diferentes profundidades do nível de água dentro do evaporatório dos minievaporímetros UFV-1 e UFV-2 sobre a evaporação.

\section{MATERIAL E MÉTODOS}

O experimento foi conduzido na Unidade de Pesquisa e Desenvolvimento do Irrigâmetro, pertencente ao Departamento de Engenharia Agrícola da UFV, em Viçosa, MG, situada a $20^{\circ} 45^{\prime}$ de latitude Sul e $42^{\circ} 51^{\prime}$ de longitude Oeste, numa altitude de $651 \mathrm{~m}$. Os elementos climáticos diários foram obtidos na Estação Climatológica do Instituto Nacional de Meteorologia (INMET), localizada no Campus da UFV, próximo à área experimental. O clima local, segundo a classificação de Köppen, é do tipo Cwb, caracterizado por clima tropical de altitude, com verão chuvoso e temperaturas amenas.

O Irrigâmetro é um aparelho que pode ser usado para estimar a evaporação, a evapotranspiração de referência e a evapotranspiração da cultura nos seus diversos estádios de desenvolvimento. Ele possui um evaporatório, no qual o nível da água é mantido constante por meio de um sistema semelhante ao usado no frasco de Mariotte, quatro válvulas que permitem efetuar o abastecimento de água, o escapamento de ar, a drenagem e a interconexão do tubo de alimentação com o evaporatório, e três escalas indicadoras da leitura da lâmina evaporada ou evapotranspirada, do tempo de irrigação ou da velocidade de rotação do sistema de irrigação e do momento de irrigar. No presente estudo, o equipamento foi denominado de Irrigâmetro, modificado devido à substituição do seu evaporatório pelos minievaporímetros. Estudo conduzido com o Irrigâmtro pode ser encontrado em Tagliaferre et al. (2006, 2008, 2010), Oliveira et al. (2008) e Materan et al. (2009a, 2009b). 
A evaporação foi determinada utilizando-se os minievaporímetros UFV-1 e UFV-2 e o tanque Classe A, ambos circundados com grama-batatais.

O minievaporímetro UFV-1 (Figura 1) operou como evaporatório de um Irrigâmetro modificado, sendo constituído por um recipiente cilíndrico de PVC, com diâmetro externo de 250 e interno de $244 \mathrm{~mm}$, altura de $320 \mathrm{~mm}$ e fundo localizado a $255 \mathrm{~mm}$ da borda. Por sua vez, o minievaporímetro UFV-2 (Figura 2) é dotado, também, de um evaporatório igual ao do UFV-1; possuindo, no entanto, outro recipiente cilíndrico de PVC de mesma altura, com diâmetro externo de 450 e interno de $440 \mathrm{~mm}$, o qual também armazena água, formando uma bordadura. Os dois minievaporímetros foram montados sobre estrado de madeira com $150 \mathrm{~mm}$ de altura. O Irrigâmetro modificado foi utilizado para manter o nível da água constante dentro dos minievaporímetros, além de possibilitar a medição da lâmina de água evaporada.

O fundo do evaporatório de cada minievaporímetro foi conectado ao Irrigâmetro modificado, por meio de um tubo flexível de polietileno. O Irrigâmetro modificado foi construído com tubo de leitura-alimentação de diâmetro interno de $72 \mathrm{~mm}$ e altura de $1 \mathrm{~m}$ e com escala graduada em milímetros. A relação entre as áreas internas do evaporatório e do tubo de leitura-alimentação do Irrigâmetro modificado, que era de 11,56, possibilitou uma sensibilidade na leitura da lâmina evaporada de $0,086 \mathrm{~mm}$. A evaporação foi obtida diretamente numa escala existente no aparelho

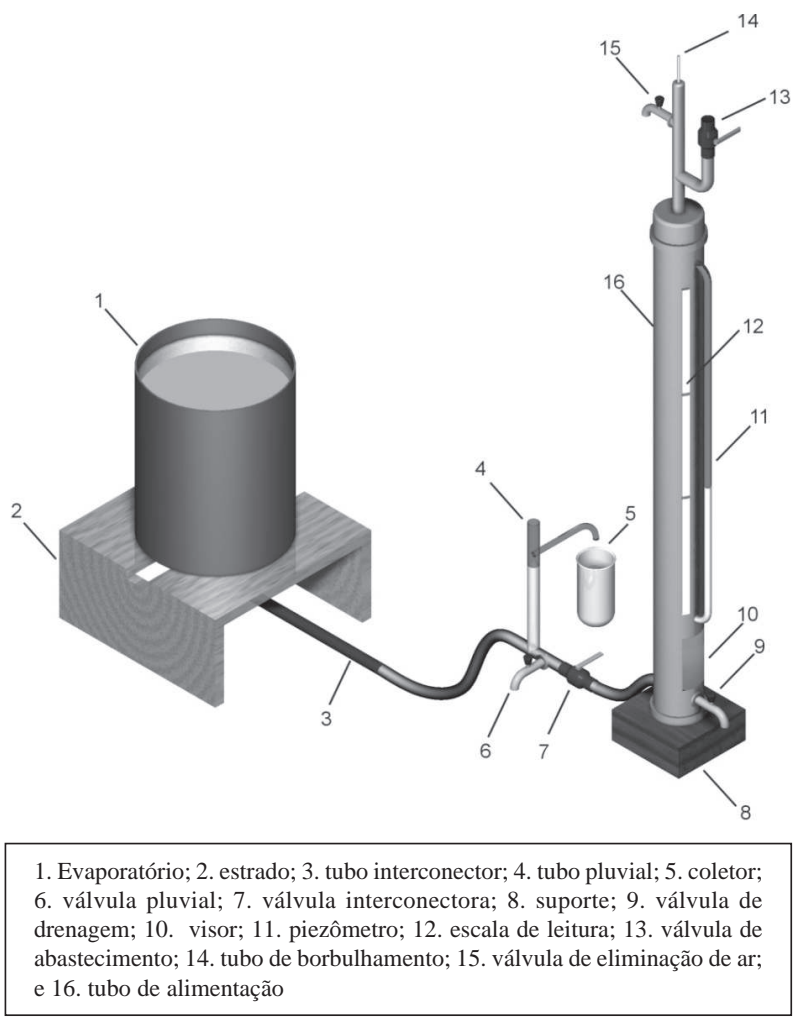

Figura 1. Minievaporímetro UFV-1 atuando como evaporatório de um Irrigâmetro modificado. pela diferença entre duas leituras consecutivas num período de 24 horas.

Na extremidade inferior do tubo de leitura-alimentação existe uma válvula de drenagem, usada para retirar a água do tubo de borbulhamento e o excesso do tubo de leituraalimentação, para zerar o aparelho. Na parte superior existem as válvulas de eliminação de ar e a de abastecimento.

Durante o reabastecimento do tubo de leitura-alimentação, a válvula interconectora deve estar fechada e as de eliminação de ar e de abastecimento devem estar abertas. Após o reabastecimento, as duas últimas válvulas são fechadas, abrindo-se a válvula de drenagem até zerar o aparelho. Em seguida, é restabelecido o seu funcionamento normal, por meio da abertura da válvula interconectora.

Em cada nível de água estudado, a superfície líquida na bordadura foi mantida aproximadamente igual à do evaporatório, por meio de reposição manual todos os dias pela manhã.

A ocorrência de chuva eleva o nível da água no evaporatório e, dependendo da sua magnitude, parte dela era drenada para o coletor, por meio do tubo pluvial. O restabelecimento do nível de água original no evaporatório era feito abrindo-se a válvula de drenagem até verificar a iminência do desprendimento de bolha de ar na extremidade inferior do tubo de borbulhamento, significando que o nível de água no evaporatório tinha retornado na posição normal. Nos dias sem chuvas a reposição de água

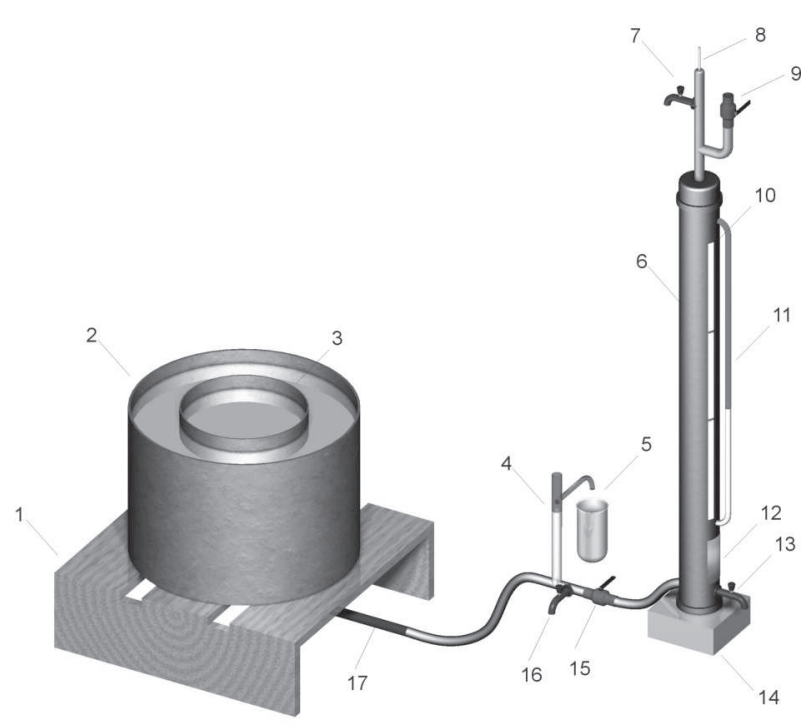

1 - Estrado; 2. bordadura; 3. evaporatório; 4. tubo pluvial; 5. coletor; 6. tubo de alimentação; 7. válvula de eliminação de ar; 8. tubo de borbulhamento; 9 . válvula de abastecimento; 10. escala de leitura; 11. piezômetro; 12. visor; 13. válvula de drenagem; 14 . suporte; 15 . válvula interconectora; 16 . válvula pluvial; e 17. tubo interconector

Figura 2. Minievaporímetro UFV-2 atuando como evaporatório de um Irrigâmetro modificado.

Rev. Ceres, Viçosa, v. 58, n.2, p. 161-167, mar/abr, 2011 
nos evaporatórios era feita automaticamente, à medida que ocorria a evaporação, pelo Irrigâmetro modificado.

A evaporação nos minievaporímetros UFV-1 $\left(\mathrm{Ev}_{\mathrm{ME1}}\right) \mathrm{e}$ UFV-2 ( $\left.\mathrm{Ev}_{\mathrm{ME} 2}\right)$ foi obtida com níveis de água no evaporatório mantidos constantes pelo irrigâmetro modificado, nas profundidades de 30, 45, 60 e $75 \mathrm{~mm}$ da borda. A medição da lâmina evaporada nos minievaporímetros e no tanque Classe $\mathrm{A}$ foi feita diariamente às $9 \mathrm{~h}$ da manhã, durante os meses de junho a dezembro de 2005. Na análise dos resultados foram excluídos os dias com ocorrência de precipitação pluvial, pois a chuva afeta a leitura da lâmina evaporada e, consequentemente, a qualidade dos dados.

Para analisar o efeito da presença da bordadura com água e as profundidades dos níveis de água nos minievaporímetros sobre a evaporação, o experimento foi montado em esquema fatorial 4 x 2 (quatro níveis de água e dois tipos de minievaporímetros), no delineamento inteiramente casualizado, com três repetições.

Os dados de evaporação foram submetidos à análise de variância e de regressão. Para o fator qualitativo, as médias foram comparadas utilizando-se o teste $\mathrm{F}$ e adotando o nível de $5 \%$ de probabilidade. Para o fator quantitativo, os modelos foram escolhidos com base na significância dos coeficientes de regressão, utilizando-se o teste " $t$ " e adotando o nível de 5\% de probabilidade no coeficiente de determinação $\left(r^{2}\right)$ e no fenômeno em estudo.

\section{RESULTADOS E DISCUSSÃO}

Nas Figuras 3, 4 e 5 encontram-se os valores médios diários dos elementos climáticos obtidos durante o período estudado.

A evaporação da água em superfícies livres em contato com a atmosfera é dependente da radiação solar incidente à superfície, da temperatura do ar, do déficit de pressão de vapor d'água sobre a superfície evaporante e da velocidade do vento. De acordo com os resultados apresentados nas Figuras 3 e 4, a umidade relativa média diária foi superior a $70 \%$, a temperatura média diária ficou em torno de 20 ${ }^{\circ} \mathrm{C}$ e a velocidade média do vento foi inferior a $2 \mathrm{~m} \mathrm{~s}^{-1}$.

A influência isolada dos elementos climáticos na evaporação de superfícies água livre, como nos tanques evaporimétricos, é difícil de ser quantificada. Hounam (1973) citou que a evaporação da água em tanques não é função apenas das condições climáticas durante determinado período, mas também das características do reservatório e do calor advectivo provenientes de áreas secas adjacentes. Essas características se inter-relacionam com as condições climáticas, dificultando a medição da sua influência na evaporação.

Na Tabela 1 encontra-se o resumo da análise de variância dos fatores níveis de água e tipos de minievaporímetros.
A evaporação foi afetada significativamente pelos níveis de água e pela presença de bordadura nos minievaporímetros. Apesar de a interação não apresentar diferença significativa a $5 \%$ de probabilidade, neste estudo optouse por fazer o desdobramento da interação estudando cada fator dentro do outro.

Na Tabela 2 estão apresentados os valores médios da evaporação obtidos nos minievaporímetros UFV-1 e UFV2 em cada nível de água estudado.

O uso do Irrigâmetro modificado proporcionou sensibilidade na leitura suficiente para detectar diferenças significativas entre as lâminas evaporadas nos dois tipos de minievaporímetros estudados. De acordo com os resultados apresentados na Tabela 2, a presença de bordadura

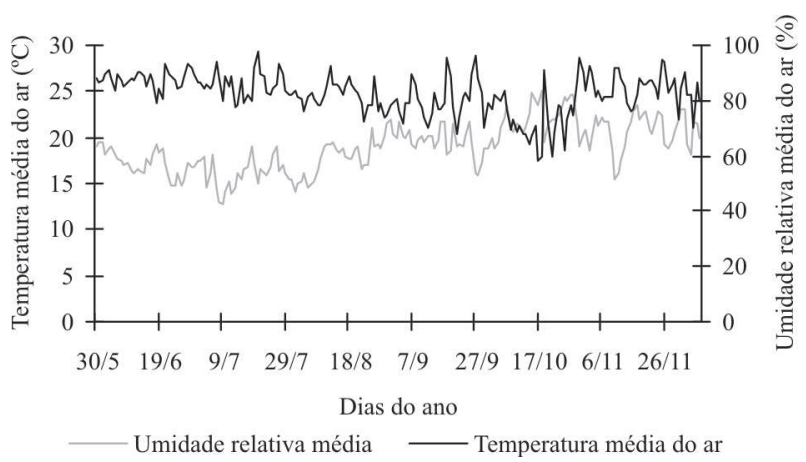

Figura 3. Valores diários da umidade relativa e da temperatura média do ar obtidos durante o período estudado.

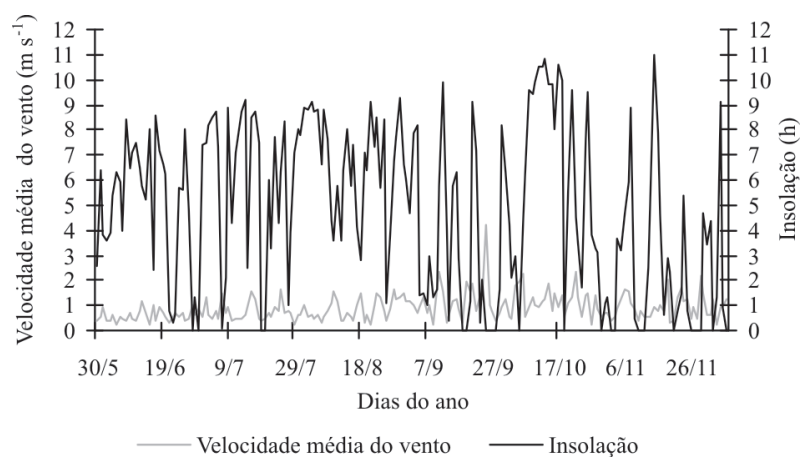

Figura 4. Valores diários da velocidade média do vento e da insolação obtidos durante o período estudado.

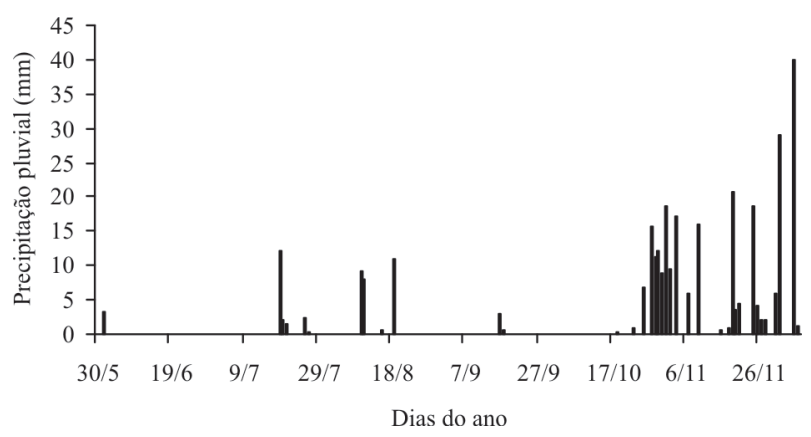

Figura 5. Valores diários de precipitação pluvial obtidos durante o período estudado. 
no minievaporímetro UFV-2 teve efeito significativo na redução da evaporação, comparativamente à ausência de bordadura no UFV-1, com valor médio de $1,10 \mathrm{~mm} \mathrm{~d}^{-1}$ entre os diversos níveis de água estudados. A bordadura no minievaporímetro UFV-2 tem a função de evitar a incidência direta dos raios solares na parede do evaporatório, reduzindo, consequentemente, a transferência de calor recebido por essa parede para a massa de água no seu interior.

No minievaporímetro UFV-1, a parede do tanque fica exposta à radiação solar, absorvendo calor que, posteriormente, é transmitido para a massa de água, alterando o seu balanço de energia, provocando maiores valores de evaporação. Essa transferência de calor é mais intensa no tanque Classe A, por ser de aço inox, material com alta condutibilidade térmica. Oroud (1998), trabalhando com tanques enterrados (Bureau of Plant Industry - BPI) e com o tanque Classe A, encontrou valores de evaporação do tanque BPI menor do que os obtidos no tanque Classe A. Segundo o autor, o tanque Classe A está mais exposto à radiação solar do que o BPI, absorvendo grande quantidade de calor pelas paredes do tanque, o que acarreta maiores valores de evaporação.

Os resultados apresentados na Tabela 3 evidenciam o efeito dos níveis de água dentro do evaporatório dos minievaporímetros UFV-1 e UFV-2, em que a variação total de 30 para $75 \mathrm{~mm}$ no nível de água reduziu a evaporação de 5,45 para 4,90 $\mathrm{mm} \mathrm{d}^{-1}$ no minievaporímetro UFV-1 e de 4,29 para 3,81 $\mathrm{mm} \mathrm{d}^{-1}$ no minievaporímetro UFV-2, representando 11,22 e 12,6\%, respectivamente. Quando o nível da água se encontra próximo à superfície, ocorre maior interceptação da radiação solar, variável que apresenta maior influência no processo de evaporação (Chang,
1971), ao mesmo tempo em que favorece a ação do vento, atuando na remoção do ar saturado sobre a superfície evaporante. Ao contrário, quando o nível da água se encontra mais distante da borda do evaporatório, aumenta o sombreamento da água contida no seu interior, em certas horas do dia, resultando em menor evaporação.

As Figuras 6 e 7 apresentam o comportamento da evaporação em função das profundidades do nível de água nos minievaporímetros UFV-1 e UFV-2, respectivamente.

Observa-se nas Figuras 6 e 7 que a evaporação diminuiu à medida que aumentou a profundidade do nível de água nos dois tipos de minievaporímetros. A redução da evaporação dentro dos intervalos de profundidades de nível de água estudado apresentou comportamento linear, tendendo ao exponencial. No entanto, como o perfil do vento acima da superfície do solo é logaritmo, o modelo exponencial foi escolhido por representar melhor o fenômeno estudado.

Nas Figuras 8 a 11 estão apresentados os valores de evaporação da água obtidos no tanque Classe $\mathrm{A}$ e nos minievaporímetros UFV-1 $\left(\mathrm{Ev}_{\mathrm{ME} 1}\right)$ e UFV-2 $\left(\mathrm{Ev}_{\mathrm{ME} 2}\right)$, nos

Tabela 3. Valores médios da evaporação obtidos nos minievaporímetros operando com níveis de água iguais a 30, 45, 60 e $75 \mathrm{~mm}$ da borda

\begin{tabular}{|c|c|c|}
\hline \multirow{3}{*}{$\begin{array}{l}\text { Profundidades dos } \\
\text { níveis de água }\end{array}$} & \multicolumn{2}{|c|}{ Minievaporímetros } \\
\hline & UFV1 & UFV2 \\
\hline & \multicolumn{2}{|c|}{$\operatorname{Evaporação~}\left(\mathrm{mm} \mathrm{d}^{-1}\right)$} \\
\hline 30 & 5,45 & 4,29 \\
\hline 45 & 5,19 & 4,11 \\
\hline 60 & 5,03 & 3,94 \\
\hline 75 & 4,90 & 3,81 \\
\hline
\end{tabular}

Tabela 1. Resumo da análise de variância das variáveis profundidades do nível de água e tipos de minievaporímetros

\begin{tabular}{lcc}
\hline Fonte de Variação & GL & QM \\
\hline Profundidades do nível de água & 3 & $0,3047^{*}$ \\
Minievaporímetro & 1 & $7,3532^{*}$ \\
Profundidades do nível de água x minievaporímetro & 3 & $0,001467^{\mathrm{ns}}$ \\
Resíduo & 16 & 0,005384 \\
\hline Coeficiente de variação (\%) & 1,60 \\
\hline
\end{tabular}

*Significativo a $5 \%$ de probabilidade, pelo teste $\mathrm{F}$.

${ }^{n s}$ Não significativo a $5 \%$ de probabilidade.

Tabela 2. Valores médios da evaporação obtidos nos minievaporímetros UFV-1 e UFV-2, com níveis de água iguais a 30, 45, 60 e 75 mm da borda

\begin{tabular}{lcccc}
\hline & \multicolumn{4}{c}{ Profundidades dos níveis de água } \\
\cline { 2 - 4 } Minievaporímetro & $\mathbf{3 0 ~ \mathbf { ~ m }}$ & $\mathbf{4 5} \mathbf{~ m m}$ & $\mathbf{6 0} \mathbf{~ m m}$ & $\mathbf{7 5} \mathbf{~ m m}$ \\
\cline { 2 - 4 } & & \multicolumn{4}{c}{ Evaporação $\left(\mathbf{m m ~ d} \mathbf{~ d}^{-1}\right)$} \\
\hline UFV-1 & $5,45 \mathrm{~A}$ & $5,19 \mathrm{~A}$ & $5,03 \mathrm{~A}$ & $4,90 \mathrm{~A}$ \\
UFV-2 & $4,29 \mathrm{~B}$ & $4,11 \mathrm{~B}$ & $3,94 \mathrm{~B}$ & $3,81 \mathrm{~B}$ \\
\hline
\end{tabular}

As médias seguidas de pelo menos uma letra igual na coluna não diferem entre si, a 5\% de probabilidade, pelo teste de Tukey. 
níveis de água iguais a 30, 45, 60 e $75 \mathrm{~mm}$ da borda, respectivamente.

A evaporação da água ocorrida nos minievaporímetros UFV-1 e UFV-2 e no tanque Classe A apresentou a mesma tendência, a qual não foi afetada pela redução na área exposta e pelo tipo de material do tanque. Com relação à magnitude dos valores de evaporação, verificou-se que houve aumento na evaporação obtida nos minievaporímetros, em comparação com o tanque Classe A. Sleight (1917) e Gangopadhyaya et al. (1966), em estudos conduzidos com tanque evaporimétrico de vários tamanhos, mostraram que a evaporação decresce exponencialmente

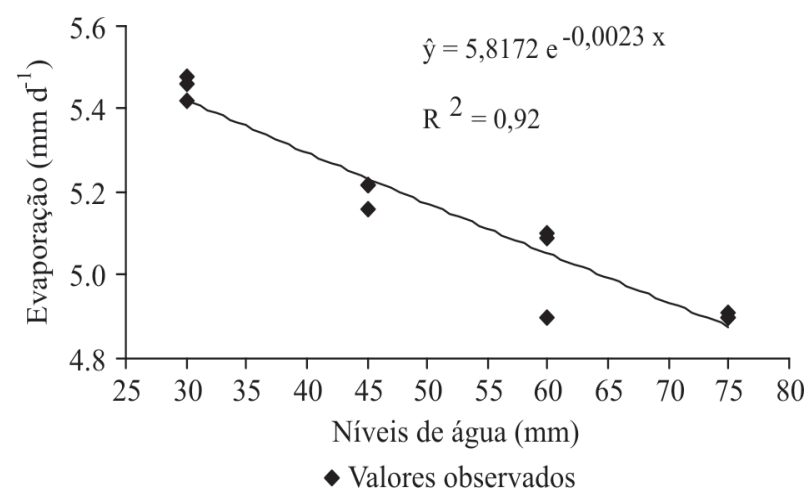

Figura 6. Estimativa da evaporação em razão da profundidade dos níveis de água no minievaporímetro UFV-1.

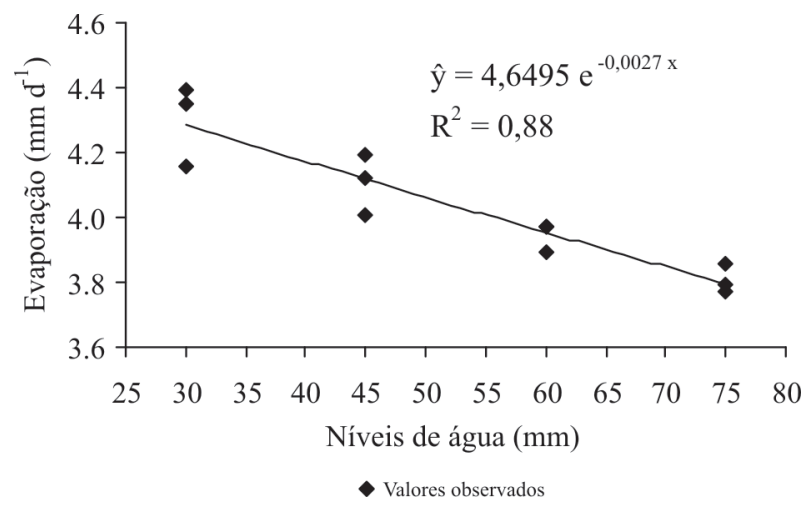

Figura 7. Estimativa da evaporação em razão da profundidade dos níveis de água no minievaporímetro UFV-2.

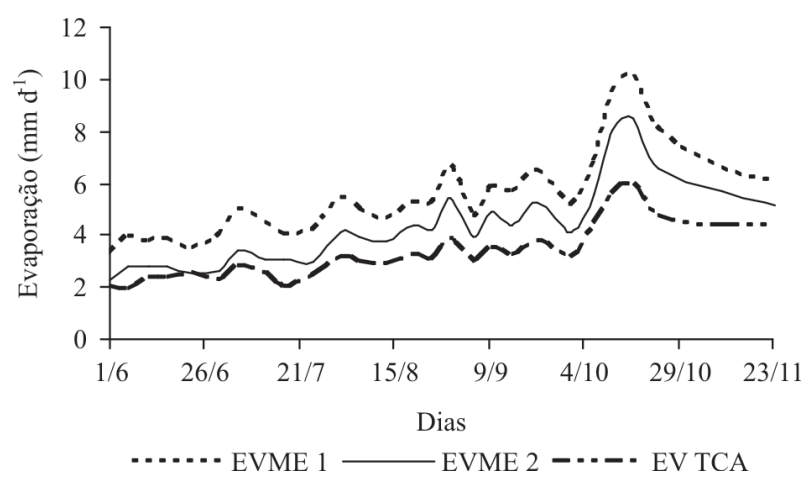

Figura 8. Evaporação no tanque Classe A e nos minievaporímetros UFV-1 e UFV-2, com nível de água a $30 \mathrm{~mm}$ da borda. com o aumento da área exposta à atmosfera. Isso ocorre porque o vento, ao passar sobre a superfície evaporante de tamanho maior, torna-se mais úmido, reduzindo o seu poder evaporante.

Os resultados observados nas Figuras 8 a 11 evidenciaram o efeito integrado da bordadura e das profundidades dos níveis de água na evaporação obtidas nos minievaporímetros. A área interna do evaporatório dos minievaporímetros é cerca de 25 vezes menor que a do tanque Classe A e, no entanto, o valor de evaporação obtida no minievaporímetro UFV-2, com nível de água igual a $75 \mathrm{~mm}$ da borda, tendeu a se aproximar do valor

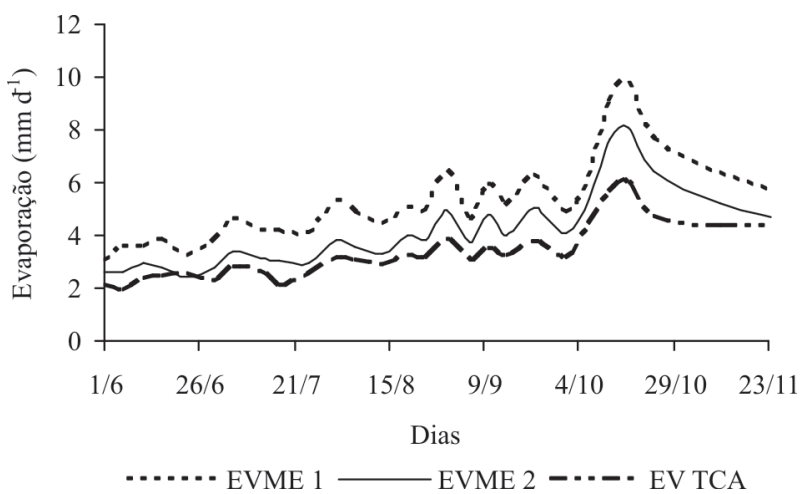

Figura 9. Evaporação no tanque Classe A e nos minievaporímetros UFV-1 e UFV-2, com nível de água a $45 \mathrm{~mm}$ da borda.

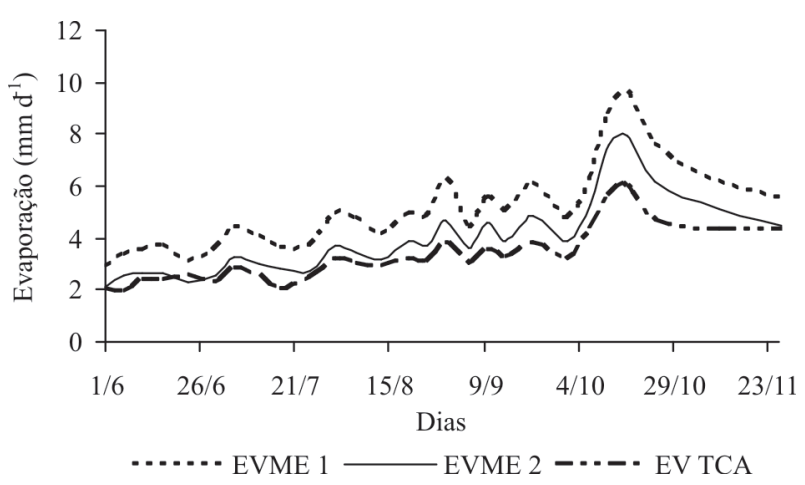

Figura 10. Evaporação no tanque Classe A e nos minievaporímetros UFV-1 e UFV-2, com nível de água a $60 \mathrm{~mm}$ da borda.

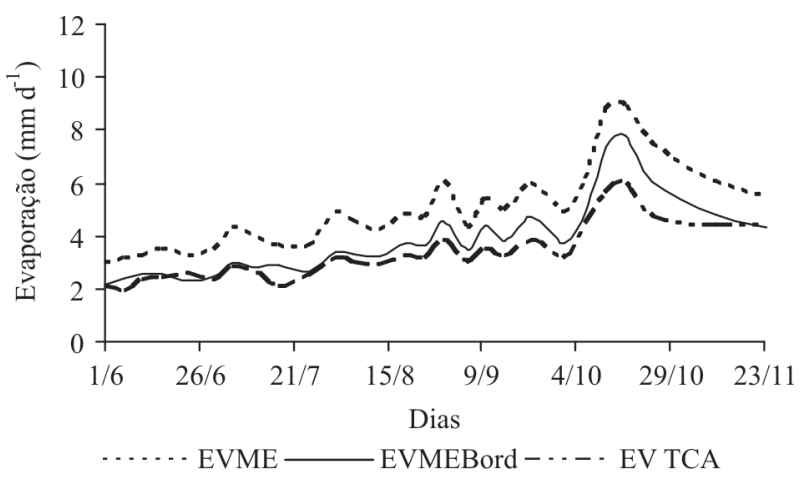

Figura 11. Evaporação no tanque Classe A e nos minievaporímetros UFV-1 e UFV-2, com nível de água a $75 \mathrm{~mm}$ da borda. 
obtido no tanque Classe A. Isso demonstra que a extensão da área do tanque Classe A foi compensada pela profundidade do nível da água nos minievaporímetros, tendendo a igualar os valores de evaporação, em decorrência do efeito do sombreamento da água e da menor remoção do ar saturado sobre a superfície evaporante pelo vento. A evaporação total ocorrida nos minievaporímetros UFV-1 e UFV-2 na profundidade de $75 \mathrm{~mm}$ e no tanque Classe A, durante o período analisado, foi de 662,12; 513,79; e 444,11 mm, respectivamente. Assim, a evaporação ocorrida no minievaporímetro UFV-1 foi superior à do tanque Classe A em 49\%, sendo de $15,7 \%$ no minievaporímetro UFV-2.

Os resultados apresentados neste estudo evidenciam a necessidade de novos estudos que possibilitem determinar um nível de água nos minievaporímetros que forneçam valores de evaporação iguais aos obtidos no tanque Classe A ou um nível de água nos minievaporímetros, quanto no tanque Classe A, que forneça uma leitura direta da evapotranspiração de referência sem o uso do coeficiente do tanque.

\section{CONCLUSÕES}

Diante dos resultados apresentados, pode-se concluir que:

A bordadura com água reduziu a evaporação no minievaporímetro UFV-2 em 1,10 $\mathrm{mm} \mathrm{d}^{-1}$, em média, nas diferentes profundidades dos níveis de água estudados, comparativamente ao minievaporímetro UFV-1.

À medida que aumentou a profundidade do nível de água no evaporatório dos dois tipos de minievaporímetros a evaporação diminuiu e se aproximou do valor obtido no tanque Classe A.

O aumento na profundidade dos níveis de água nos minievaporímetros UFV-1 e UFV-2 de 30 para $75 \mathrm{~mm}$ reduziu a evaporação de 5,45 para $4,9 \mathrm{~mm} \mathrm{~d}^{-1} \mathrm{e}$ de 4,29 para 3,81 $\mathrm{mm} \mathrm{d}^{-1}$, respectivamente.

\section{AGRADECIMENTOS}

Ao Conselho Nacional de Desenvolvimento Científico e Tecnológico (CNPq) e à Coordenação de Aperfeiçoamento de Pessoal de Nível Superior (CAPES), pelo auxílio financeiro.

\section{REFERÊNCIAS}

Camargo AP de \& Camargo MBP de (2000) Uma revisão analítica da evapotranspiração potencial. Bragantia, 59:125-137.

Chang J (1971) Climate and agriculture. Chicago, Aldine Publishing. 296 p.

Doorenbos J \& Pruitt JO (1977) Crop water requeriment. Rome, FAO. 144p. (FAO Irrigation and Drainage - Paper 24).
Gangopadhyaya M, Harbeck GEJR, Nordenson TJ, Omar MH \& Uryvaev VA (1966) Measurement and estimation of evaporation and evapotranspiratin. Geneva, World Meteorological Organization. 121p. (Tech. Note $\mathrm{N}^{\circ} 83$, WMO-No 201, TP 105).

Hounam CE (1973) Comparison between pan and lake evaporation. Geneva, World Meteorological Organization. 52p. (Tech. Note $\mathrm{N}^{\circ} 126, \mathrm{WMO}^{\mathrm{N}}$ 354).

Kohler MA \& Parmele LH (1967) Generalized estimates of freewater evaporation. Water Resources Research, 3:997-1005.

Materán FJV, Oliveira RA de, Sediyama GC, Cecon PR, Ruiz HA \& Tagliaferre C (2009a) Minilisímetro com lençol freático constante operando com Irrigâmetro ${ }^{\circledR}$ para medida da evapotranspiração de referência. Revista UDO Agrícola, 9:243-258.

Materán FJV, Oliveira RA de, Cecon PR, Sediyama GC, Martinez HEP \& Tagliaferre C (2009b) Lisímetro com lençol freático constante operando com Irrigâmetro® modificado para medida da evapotranspiração de referência. Revista UDO Agrícola, 9:364-375.

Monteny B (1972) Evapotranspiration of diferents couverts vegetaux in region mediterranéene semi-aride. Agricultural Meteorology, 10:19-38.

Oliveira RA de, Tagliaferre C, Sediyama GC, Materán FJV \& Cecon PR (2008) Desempenho do Irrigâmetro na estimativa da evapotranspiração de referência. Revista Brasileira de Engenharia Agrícola Ambiental, 12:166-173.

Oroud I M (1998) The influence of heat conduction on evaporation from sunken pans in hot, dry environment. Journal of Hydrology, 210:1-10.

Prueger JH, Hipps LE \& Coopper DI (1996) Evaporation and development of the local boundary layer over an irrigated surface in an arid region. Agricultural and Forest Meteorology, 78:223237.

Rosenberg NJ (1972) Frequency of potential evapotranspiration rates in Central Great Plains. Journal of Irrigation and Drainage, 98:203-206.

Sleight RB (1917) Evaporation from the surfaces of water and river-bed materials. Journal of Agricultural Research, 10:209262.

Tagliaferre C, Oliveira RA de, Oliveira EM de, Baptestini JCB \& Santos L da C (2010) Desempenho do irrigâmetro no manejo da água de irrigação na cultura do feijoeiro. Caatinga, 23:110-117.

Tagliaferre C, Oliveira RA de, Sediyama GC, Cecon PR, Deniculi W, Martinez MA \& Materán FJV (2006) Estimativa da evapotranspiração de referência usando Minievaporímetro operando com irrigâmetro modificado. Engenharia na Agricultura, $14: 212-223$.

Tagliaferre C, Oliveira RA de, Sediyama GC, Cecon PR, Martinez MA \&, Materán FJV (2008) Estimativa da evapotranspiração de referência usando Minievaporímetro com bordadura. Engenharia na Agricultura, 16:87-98.

Valero JA de J \& Mañas FJM de S O (1993) El calculo y la estimacion de la evapotranspiracion. In: Mañas FJ M de SO \& Valero JA de J (Eds.) Agronomia del riego. Madrid, Mundi-Prensa. p.373-446.

Rev. Ceres, Viçosa, v. 58, n.2, p. 161-167, mar/abr, 2011 